\title{
LORENZ SYSTEM IN THERMODYNAMICAL MODELLING OF LEUKEMIA MALIGNANCY
}

\author{
IGOR ALEXEEV \\ ig.v.alexeev@gmail.com
}

\begin{abstract}
Entropy rising within normal hematopoiesis is the core idea of the proposed thermodynamical model of malignancy in leukemia. Mathematically its description is supposed to be similar to the Lorenz system of ordinary differential equations for simplified processes of heat flow in fluids. The model provides description of remission and relapse in leukemia as two hierarchical and qualitatively different states of normal hematopoiesis with their own phase spaces. Phase space transition is possible through pitchfork bifurcation, which is considered as the common symmetrical scenario for relapse, induced remission and spontaneous remission of leukemia. Cytopenia is regarded as an adaptive reaction of hematopoiesis to entropy increase caused by leukemia clone. The following hypotheses are formulated: a) Percentage of leukemia cells in marrow as criterion of remission or relapse is not necessarily constant but a variable value; b) Probability of getting remission depends upon normal hematopoiesis reaching bifurcation; c) Duration of remission depends upon eradication of leukemia cells in induction or consolidation therapies; d) Excessively high doses of chemotherapy in consolidation might induce relapse.
\end{abstract}

Keywords: Leukemia, relapse, spontaneous remission, Lorenz system, thermodynamics, entropy.

\section{Foreword}

Traditionally leukemia is considered as a unidirectional process of growth and expansion of leukemia clone into bone marrow. Resulting failure of normal hematopoiesis and involvement of other organs are regarded as complications of the disease. The corresponding model of leukemia as a proliferating tumor is based on its numerical aspect - amount of leukemia cells over time. Another aspect of leukemia - malignant effect of leukemia cells on normal hematopoiesis is often overlooked in modelling, despite the fact that it greatly determines the course of the disease and survival prognosis for the patient.

This article presents a model of leukemia malignancy as a process of entropy rising within normal haematopoiesis, caused by leukemia clone. Why thermodynamics is needed in description of leukemia 
and what to expect from it? Thermodynamics explains why something happens but does not show how it happens. It does not provide description of molecular mechanisms behind relapse or remission of leukemia, however it explains why spontaneous processes in leukemia are possible. Thermodynamics provides more accurate description of nonlinear aspect of leukemia dynamics than computational models of proliferating leukemia clone.

Mathematical description of entropy rising within normal hematopoiesis in leukemia is probably similar to entropy rising in heating shallow layer of fluid, known as Lorenz system. The role of leukemia clone in this context appears to be only a passive "heat" source while induced remission, spontaneous remission and relapse are considered as common manifestations of the same process of phase space transition through bifurcation in normal hematopoiesis.

The biggest weakness of this model is presentation of remission and relapse as two qualitatively different states of hematopoiesis in leukemia. The lack of experimental evidence for molecular mechanisms specific for remission or relapse can leave this model unsubstantiated. In addition, the model cannot be applied easily to analysis of solid cancers since the modelling conditions are different.

Thermodynamics provides a powerful tool for modelling different aspects of leukemia and thus it seems possible to build several thermodynamical models as alternatives to traditional linear model of leukemic clone expansion. Non-equilibrium aspect of leukemia might be modelled as a two-component unbalanced system of normal hematopoiesis and leukemic clone making a biological oscillator with entropy flow between its parts. A hybrid model of leukemia as a process of entropy rising within normal hematopoiesis and an upper level model of leukemia as a biological oscillator might be a next step in our modelling efforts.

\section{Introduction.}

1.1 Leukemia as a disease. Leukemia is a group of cancers involving blood cells of bone marrow. Leukemia is the $11^{\text {th }}$ most common cancer worldwide, with around 352,00o new cases diagnosed in 2012 [13]. Malignant transformation usually occurs at the level of a pluripotent stem cell or committed progenitor cells with more limited capacity for differentiation. It is generally accepted, that abnormally high proliferation rate and longevity lead to expansion of leukemic clone in bone marrow and often into various other organs and sites, such as liver, spleen, lymph nodes, central nervous system, kidneys and gonads. Resulting disruption of hematopoiesis cause anemia, infection, easy bruising or bleeding. In a typical case of acute leukemia such symptoms have usually been present for only days to weeks before diagnosis. Approximately $10^{12}$ leukemia cell have been estimated to be present by that time [47] 
bioRxiv preprint doi: https://doi.org/10.1101/034132; this version posted January 1, 2017. The copyright holder for this preprint (which was not certified by peer review) is the author/funder, who has granted bioRxiv a license to display the preprint in perpetuity. It is made available under aCC-BY-NC-ND 4.0 International license.

which indicates that the growing leukemic clone coexisted with normal hematopoiesis for months without any apparent signs of its presence.

1.2 New mutations in leukemic clone as a basis of leukemia progression. Relatively recent experimental evidence suggests that acute myeloid leukemia may originate from multiple clones of malignant cells [9]. For chronic lymphocytic leukemia certain genetic events are found in the majority of cells which are considered as 'clonal driver mutations', whereas others, present only in a fraction of the tumor, are deemed to be 'subclonal driver mutations' [43]. Sequencing studies revealed about 140 genes that when altered by intragenic mutations can act as driver mutations during tumorigenesis [46]. The presence of sub-clonal driver mutations was associated with reduced survival in chronic lymphocytic leukemia [24], and it seems that the degree of subclonality might serve as a cancer marker per se. Higher diversity is related to a higher mutation rate or longer tumor evolution with more replications [41].

1.3 Possible mechanisms of normal hematopoiesis disruption in leukemia. Interaction between the healthy and cancer cell lines is often described through a competition for physical space resulting in an increased cellular degradation. This is consistent with the observation of an increase of markers for cell death such as lactate dehydrogenase [3, 11, 22, 42]. Several mechanisms underlying this spatial competition have been proposed: overcrowding which results in extinction of cells [17]; competition for a limited surface niche expressing certain receptors [4, 48]; and apoptosis if no contacts to these receptors can be established [15]. Other possible mechanisms include induction of cytopenia by impeding hematopoietic stem cells proliferation and differentiation [26] and competition for energy and nutrients [39]. Although molecular mechanisms of disruption are not known, at the level of cell populations hematopoiesis disruption is consistent with competitive exclusion principle (also known under several other names including Volterra-Lotka Law), which postulates that populations competing for the same limiting resource in one homogeneous habitat cannot coexist long enough [18, 21]. However, it is still debatable whether competitive exclusion principle developed for ecosystems can be applied for processes at cellular level.

1.4 Clinical remission and relapse as two states of hematopoiesis in leukemia. The first manifestation of leukemia means not only expansion of leukemia clone into marrow and other organs but also disruption of normal hematopoiesis leading to severe complications of the disease. The goal of induction therapy of leukemia is attainment of a complete remission, which usually requires a period of marrow aplasia, or a "morphologic leukemia-free state," following induction chemotherapy [47]. Complete remission is currently defined as restoration of normal hematopoiesis with a blast cell fraction of less than $5 \%$ by light microscopic examination of the bone marrow. This relatively liberal definition reflects the difficulty of identifying leukemic blasts in regenerating marrow by morphologic criteria alone. Thus, patients with nearly $5 \%$ leukemic blast cells in their marrow specimens can harbor 
as many as $10^{10}$ leukemia cells $[5,37]$. Recurrence of leukemia, called relapse, after therapy is a common problem of leukemia. The goal of post-remission or consolidation therapy is to prolong complete remission by delaying or preventing relapse and to maximize the chance of cure [47]. In a typical acute leukemia with chemotherapy the leukemic process is staged strictly as relapse or remission while correlations between the kinetic parameters of the normal and leukemic populations are suggested to characterize the leukemic state [10].

1.5 Spontaneous remission of leukemia. Remission of leukemia without any specific therapy, called spontaneous remission, is an extremely rare and exceptional, relatively well documented but poorly understood phenomenon. Spontaneous remission of acute myeloid leukemia is almost always transient event, with a mean duration in the literature of 7.7 months (range 1-36) [14]. In a typical case of spontaneous remission the full restoration of normal hematopoiesis and disappearance of blast cells occur in patient with acute leukemia and concurrent infection $[2,7,12,16,23,27,31,32,33,36,45]$, blood transfusion $[2,14,25,36,38]$ or cytokine injection [19, 44]. The underlying molecular mechanisms of spontaneous remission are still unknown. A potential role of bacterial or fungal infections and blood transfusions was suggested in spontaneous remission occurrence by triggering antileukemic and immune responses [35]. Activation of cytotoxic T lymphocytes and macrophages in conjunction with an increased cytotoxicity of Natural Killer cells as well as cytokines of the immune system such as tumor necrosis factor, interferon gamma, and interleukin-2, released during infection may play a role in the occurrence of spontaneous remission [6, 20, 29, 30, 31]. However, no clear link between spontaneous remission and infection or immune response was reported in at least one case [8]. In another report spontaneous remission was detected after termination of pregnancy [27].

\section{Lorenz system}

Dynamical biological or physical systems display a variety of linear and nonlinear behaviors that can be described by corresponding mathematical models. Despite the diverse nature of processes, resulting mathematical description is quite similar, so it seems possible to understand some aspects of leukemia dynamics with the help of other models. This possibility of common mathematical description will be used to highlight similarities between leukemia and heat distribution in fluid flows.

Since leukemia increases entropy of normal hematopoiesis, Lorenz system is suggested to be used for modelling as it reflects a similar process of entropy rising in a uniformly heated and cooled shallow layer of fluid. Edward Norton Lorenz modeled weather and motion of air as it is heated and found that 
while being severely truncated version of Navier-Stokes equations (which arise from applying Newton's second law to viscous fluid motion), the system still preserves many of its characteristics. Detailed analysis of the Lorenz equations is out of scope of this article, however it is readily available and is commonly used as a simplified model of nonlinear system. Some terms of the theory of dynamical systems are used here when necessary in context of leukemia modelling. An introduction to the theory of dynamical systems is available [40].

In brief, Lorenz model for convection is the system of three ordinary differential equations $(1),(2),(3)$ :

$$
\begin{gathered}
\frac{d x_{1}}{d t}=-P x_{1}+P x_{2} \\
\frac{d x_{2}}{d t}=-x_{1} x_{3}+R x_{1}-x_{2} \\
\frac{d x_{3}}{d t}=x_{1} x_{2}-B x_{3} .
\end{gathered}
$$

Given $\mathrm{P}=10$ and $\mathrm{B}=8 / 3$ (those are any of constant parameters) the system behavior depends upon $\mathrm{R}$ control parameter which reflects heating and relates to entropy of the system. For $R<1$ the origin is the only stable steady state (diagram 1). This situation corresponds to no convection in heating fluids. At $R=1$ there are two new stable steady states of the system where $x(t)>0$ and $x(t)<0$. These conditions correspond to the state of steady convection in fluids. There is also a pitchfork bifurcation, where a state transition between them is possible. The system remains stable until $\mathrm{R}=\mathbf{2 4 . 7 4}$ (diagrams 2 and 3 ). Lorenz found that the system behaves chaotically for R>24.74 when it starts with a rotation around one of the focuses with an amplitude increasing with time, thereby forming a divergent spiral. After a number of such oscillations, the system suddenly goes toward the second available focus through a bifurcation and it continues an oscillatory motion around the second available focus along a divergent spiral. After a certain number of oscillations around this focus, the system jumps back to the vicinity of the previous focus, from which it again begins a new divergent oscillatory trajectory (diagram 4) (based on [34]). 


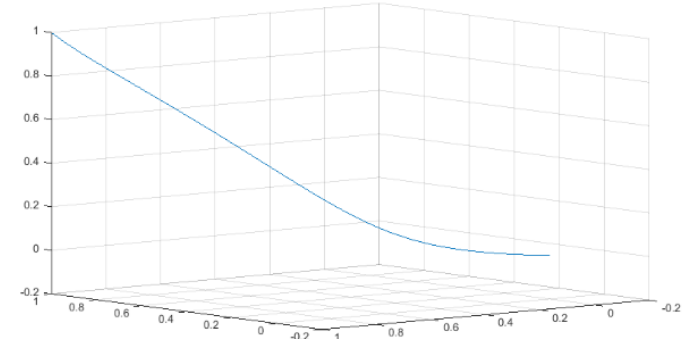

Diagram 1. $\mathrm{P}=10$ and $\mathrm{B}=8 / 3 \mathrm{R}=1 / 2$

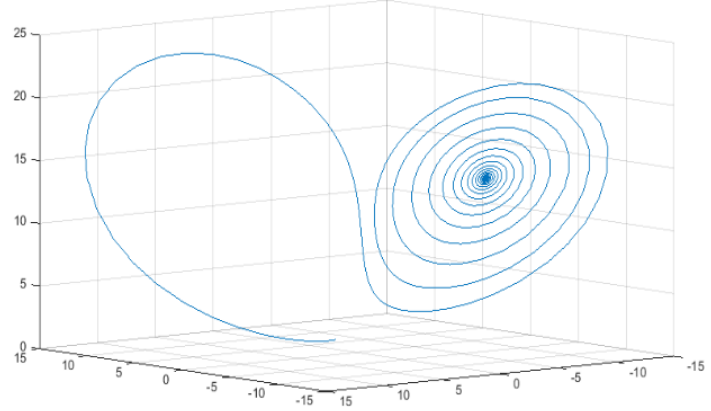

Diagram 3. $\mathrm{P}=10$ and $\mathrm{B}=8 / 3 \mathrm{R}=15$

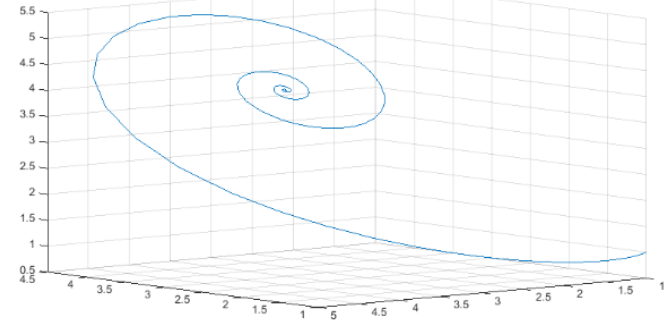

Diagram 2. $\mathrm{P}=10$ and $\mathrm{B}=8 / 3 \mathrm{R}=5$

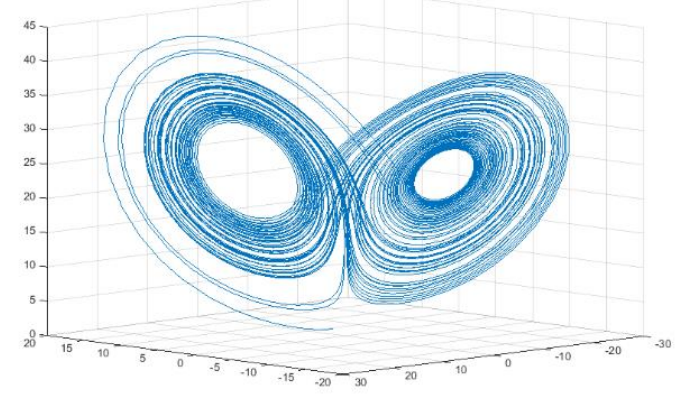

Diagram 4. $\mathrm{P}=10$ and $\mathrm{B}=8 / 3 \mathrm{R}=25$

Diagrams 1-4. Lorenz attractor. From initial steady state (diagram 1) the system compartmentalizes (diagrams 2 and 3) making two new steady states and pitchfork bifurcation. With subsequent entropy increase the system loses stability (diagram 4).

\section{Discussion}

Leukemia is an incarnation of chaos. The chaos begins from one or several mutations in cell genome producing independently growing and quickly changing cell population of tumor. At certain moment it starts to affect the functioning of normal hematopoiesis probably competing with it for some common resources or indirectly disrupting its regulatory networks. Degree of disruption or malignancy determines survival prognosis for a patient with untreated disease. It is important to make distinction between the tumor per se and its disruptive effect on the normal hematopoiesis. If left untreated, a patient will be suffering because of failure of normal hematopoietic lineages caused by leukemia cells but not because of their presence.

Malignancy or harmful effect of leukemia clone on normal hematopoiesis can be expressed numerically through their approximate linear models. At the same time, in terms of thermodynamics 
bioRxiv preprint doi: https://doi.org/10.1101/034132; this version posted January 1, 2017. The copyright holder for this preprint (which was not certified by peer review) is the author/funder, who has granted bioRxiv a license to display the preprint in perpetuity. It is made available under aCC-BY-NC-ND 4.0 International license.

harmful effect of leukemia on normal hematopoiesis can be described as an increase of its entropy, exceeding a certain physiological norm. These two approaches to description of leukemia demonstrate two aspects in its modelling: quantitative and dynamic. These aspects reflect different emphases and are not in conflict with one another. Quantitative or numerical aspect describes cellularity or cell composition of bone marrow as absolute and relative amount of cells. It reflects the stage of leukemia and the state of normal hematopoiesis. Dynamic aspect of leukemia modelling characterizes complex behavior of hematopoiesis in leukemia with transitions between relapse and remission as distinctive qualitative states of normal hematopoiesis. For our modelling purposes we use mathematical description of a similar process of entropy flow in a uniformly heated shallow layer of fluid known as Lorenz system. Similarities between two processes are not only entropy flows but also the same modeling conditions which are homogenous medium of fluid in Lorenz system and homogenous medium of bone marrow in leukemia.

Graphical solution of ordinary differential equations of Lorenz system is an abstraction which provides three clues for understanding leukemia. Firstly, at certain level of entropy the system compartmentalizes passing from an only stable state (diagram 1 ) to a new steady state with two available focuses within their phase spaces (diagrams 2 and 3). In our model of leukemia it indicates that upon appearance of leukemia clone normal hematopoiesis exists in two qualitatively different states - one state corresponds to remission and another to relapse. In other words, remission and relapse exist in leukemia as different states of hematopoiesis regardless of processes within tumor. Leukemia clone in this context is only a "heat" source which destroys normal hematopoiesis by increasing its entropy.

Idea of remission and relapse as two qualitatively different stable states of hematopoiesis in leukemia is derived directly from graphical solutions of Lorenz equations for R value greater than 15 (diagrams 3 and 4), however this assumption is still the biggest weakness of the proposed model, since no experimental evidence for any underlying molecular mechanisms in normal hematopoiesis is known. The best possible candidate for such a mechanism would be a signalling pathway for certain hematopoietic lineages which is active in remission and absent or clearly suppressed in relapse or vice versa.

Secondly, there is a pitchfork bifurcation between the phase spaces indicating an opportunity of swap between them. Bifurcation also indicates that remission and relapse are hierarchical states of hematopoiesis i.e. hematopoiesis can exist in one of the states but not in both of them simultaneously. Remission and relapse are the only two stable states of hematopoiesis in the model which can be observed clinically but pitchfork bifurcation is an unstable state of hematopoiesis. Finally, at a certain level of entropy the system loses stability making possible spontaneous phase space transition through the bifurcation (diagram 4). For our model of leukemia the chaotic behavior of Lorenz system 
bioRxiv preprint doi: https://doi.org/10.1101/034132; this version posted January 1, 2017. The copyright holder for this preprint (which was not certified by peer review) is the author/funder, who has granted bioRxiv a license to display the preprint in perpetuity. It is made available under aCC-BY-NC-ND 4.0 International license.

corresponds to spontaneous remission in the course of the disease. Concurrent infection, blood transfusions or cytokine injections are factors contributing to stability loss and thus facilitating the spontaneous state transition. Spontaneous remission is usually transient since leukemia clone prevails.

Relapse of leukemia can be considered as another possible symmetrical scenario of spontaneous states swap. It involves reaching of bifurcation by hematopoiesis in the state of remission. Spontaneous remission and "spontaneous relapse" are the two symmetrical manifestations of the same process of the phase space transition through bifurcation. Successful course of chemotherapy should result in a period of marrow aplasia, which corresponds to bifurcation. Thus, the role of chemotherapy in leukemia appears to be dual since it is not limited only to eradication of leukemia clone. Chemotherapy has also a regulatory role driving normal hematopoiesis in relapse to bifurcation making possible state swap which results in remission.

According to the model, there are two ways of reaching remission in leukemia. Firstly, when normal hematopoiesis reaches bifurcation in relapse by chemotherapy or spontaneously. Such a remission can be of any duration depending on remaining leukemia clone or effectiveness of consolidation therapy. Secondly, an eradication of leukemia clone as a factor of entropy rise. In an ideal case of complete eradication it would mean complete cure of the disease with subsequent return of hematopoiesis to normal type. Relapse of leukemia can also be considered as a spontaneous event of reaching bifurcation but in the state of remission. While going further one can suggest that excessively high doses of chemotherapy in consolidation therapy could also induce relapse as state swap in remission.

Cytopenia observed at the first manifestation of leukemia can be interpreted as an adaptive reaction of hematopoiesis to entropy increase caused by leukemia clone [1]. It would be more appropriate to explain it by an idea of homeostasis as maintenance of thermodynamic temperature. With appearance of leukemia clone and subsequent increase of thermodynamic temperature of hematopoiesis, homeostasis of the whole system is maintained resulting in decrease of thermodynamic temperature of normal hematopoiesis. The latter leads to stem and progenitor cell proliferation and differentiation rate decrease and results in cytopenia. So, the normal hematopoiesis is suppressed in leukemia by a physiological mechanism which maintains homeostasis. With appearance of leukemia clone and at a certain level of entropy the normal hematopoiesis reaches bifurcation with subsequent phase space transition. Clinically this situation corresponds to the first manifestation of the disease or to relapse.

Thus, based on the model, some hypotheses can be formulated. Definition of remission and relapse solely through the state of normal hematopoiesis leads to the following: (a) percentage of leukemia cell in marrow for relapse or remission criterion is not necessarily constant but a variable value [1]; (b) probability of getting remission depends upon reaching bifurcation; (c) Duration of induced remission 
depends mainly upon degree of eradication of leukemia cells in therapy; (d) Excessively high doses of chemotherapy in consolidation therapy can induce relapse.

All four hypotheses can be tested in laboratory and by statistical analysis, however refinement of the model appears to be more difficult. Presumably, it should include integration of both computational and dynamic aspects of leukemia clone and normal hematopoiesis interaction by a model of leukemia as a biological oscillator in terms of non-equilibrium thermodynamics. The model verification would also require development of methods for entropy assessment in cell populations on laboratory models and in humans.

Regulatory role of thermodynamic potential on cellular processes was not largely discussed. It is known that at the cellular level high temperatures and some external shock factors upregulate expression of Heat Shock Proteins, - chaperons with mainly stabilizing and protective role within cells. Those changes might be also a part of regulatory effects of entropy fluctuations on normal hematopoiesis in leukemia, however, effects of weak thermodynamic temperature on cells and cell populations are still not proven.

Most existing models describe leukemia as linear process of tumor expansion in bone marrow. Resulting failure of normal haematopoietic lineages is regarded as complication of leukemia. Presented thermodynamical model considers leukemia as a non-linear process of entropy rising within normal haematopoiesis caused by leukemia clone. Mathematical description of these events is similar to Lorenz system of differential equations for heat flow in fluids and thus the following metaphoric conclusion seems appropriate: "Leukemia is fire in blood". 
bioRxiv preprint doi: https://doi.org/10.1101/034132; this version posted January 1, 2017. The copyright holder for this preprint (which was not certified by peer review) is the author/funder, who has granted bioRxiv a license to display the preprint in perpetuity. It is made available under aCC-BY-NC-ND 4.0 International license.

\section{REFERENCES}

1. Alekseyev IV. Leukemic progression as process of adaptation (theoretical model). Med Oncol Tumor Pharmacother. 1992; 9(1):47-50.

2. Garth Beinart, Dan Jones, Lynne V. Abruzzo, Farhad Ravandi, Spontaneous Hematologic and Cytogenetic Remission in a Case of Acute Myelogenous Leukemia with Inversion 16, Clinical Leukemia, 2007, 1, 4, 243

3. Buechner T, Heinecke A. The role of prognostic factors in acute myeloid leukemia. Leukemia 10 Suppl. 1996, 1: S28-29.

4. Calvi LM, Calvi LM, Adams GB, Weibrecht KW, Weber JM, Olson DP, Knight MC, Martin RP, Schipani E, Divieti P, Bringhurst FR, Milner LA, Kronenberg HM, Scadden DT Osteoblastic cells regulate the haematopoietic stem cell niche. Nature 2003, 425: 841-6

5. Campana $\mathrm{D}$, Pui $\mathrm{C}-\mathrm{H}$. Detection of minimal residual disease in acute leukemia: methodologic advances and clinical significance. Blood; 1995, 85: 1416-1434

6. Vincent Camus, Pascaline Etancelin, Fabrice Jardin, Pascal Lenain, Nathalie Contentin, Sylvie Daliphard, Gérard Buchonnet, Emilie Lemasle, Hélène Lanic, Stéphane Leprêtre, Dominique Penther, Sydney Dubois, Hervé Tilly, Christian Bastard, Aspasia Stamatoullas, Spontaneous remission in three cases of AML M5 withNPM1mutation, Clinical Case Reports 2015, 3, 11, 955

7. Rong-Long Chen, Shih-Sung Chuang. Transient Spontaneous Remission After Tumor Lysis Syndrome Triggered by a Severe Pulmonary Infection in an Adolescent Boy With Acute Lymphoblastic Leukemia, Journal of Pediatric Hematology/Oncology, 2009, 31, 1, 76

8. Antoine Daccache, Tinoy Kizhakekuttu, James Siebert, Michael Veeder. Hematologic and Cytogenetic Spontaneous Remission in Acute Monocytic Leukemia (FAB M5b) With Trisomy 8 JCO 2007 January 20, vol. 25 no. 3 344-346

9. Ding L, Ding L, Ley TJ, Larson DE, Miller CA, Koboldt DC, Welch JS, Ritchey JK, Young MA, Lamprecht T, McLellan, et al. Clonal evolution in relapsed acute myeloid leukaemia revealed by whole-genome sequencing. Nature 2012 481: 506-10.

10. Djulbegović B, Svetina S. Mathematical model of acute myeloblastic leukaemia: an investigation of the relevant kinetic parameters. Cell Tissue Kinet. 1985 May;18(3):307-19.

11. Fanin R, Zuffa E, Fasola G, Damiani D, Gallizia C, Michieli MG, Marcuzzi P, Russo D, Visani G, Resegotti L. Serum lactate dehydrogenase is an important risk determinant in acute lymphocytic leukemia. Haematologica 1989 74: 161-65.

12. Fassas A, Sakellari I, Anagnostopoulos A, Saloum R Spontaneous remission of acute myeloid leukemia in a patient with concurrent Pneumocystis carinii pneumonia. Nouv Rev Fr Hematol 1991 33:363-364

13. Ferlay J, Soerjomataram I, Ervik M, et al. GLOBOCAN 2012 v1.o, Cancer Incidence and Mortality Worldwide: IARC CancerBase No. 11 [Internet]. Lyon, France: International Agency for Research on Cancer; 2013. Available from: http://globocan.iarc.fr), accessed December 2013.

14. Fozza, C., S. Bellizzi, S. Bonfigli, P. M. Campus, F. Dore, and M. Longinotti. Cytogenetic and hematological spontaneous remission in a case of acute myelogenous leukemia. Eur. J. Haematol. 2004, 73:219-222.

15. Garrido SM, Appelbaum FR, Willman CL, Banker DE Acute myeloid leukemia cells are protected from spontaneous and drug-induced apoptosis by direct contact with a human bone marrow stromal cell line (HS-5). Exp Hematol 2001 29: 44857 .

16. Gau JP, Young JH, Lin TH, Yang Y, Ho KC. Spontaneous remission in acute myelogenous leukemia: a case report. Zhonghua Yi Xue Za Zhi (Taipei) 1997, 59:121-125

17. Griffin JD, Lowenberg B Clonogenic cells in acute myeloblastic leukemia. Blood 1986 68: 1185-95.

18. Hardin, G. The Competitive Exclusion Principle. Science. 1960, 131, 1292-1297,

19. Hayatsu K, Nagai K, Abe A, Murakawa E, Sekiya M Complete remission during administration of rhG-CSF in acute myeloblastic leukemia with pneumonia. Rinsho Ketsueki 1994, 35:59-64

20. Jimemez, C., J. M. Ribera, E. Abad, G. Pintos, F. Milla, J. Junca, et al. Increased serum tumour necrosis factor during transient remission in acute leukaemia. Lancet 1993, 341:1600. 
bioRxiv preprint doi: https://doi.org/10.1101/034132; this version posted January 1, 2017. The copyright holder for this preprint (which was not certified by peer review) is the author/funder, who has granted bioRxiv a license to display the preprint in perpetuity. It is made available under aCC-BY-NC-ND 4.0 International license.

21. Kalmykov L, Kalmykov V. Verification and reformulation of the competitive exclusion principle. Chaos, Solutions \& Fractals 2013, 56, 124-31.

22. Kornberg A, Polliack A. Serum lactic dehydrogenase (LDH) levels in acute leukemia: marked elevations in lymphoblastic leukemia. Blood 1980, 56: 351-5.

23. Anne Helene Køstner, Rakel Fuglesang Johansen, Henrik Schmidt, Ingolf Mølle, Regression in cancer following fever and acute infection, Acta Oncologica, 2013, 52, 2, 455

24. Landau DA, Carter SL, Stojanov $P$, McKenna A, Stevenson $K$, Lawrence MS, Sougnez $C$, Stewart $C$, Sivachenko A, Wang L, Wan Y, Zhang W, Shukla SA, Vartanov A, Fernandes SM, Saksena G, Cibulskis K, Tesar B, Gabriel S, Hacohen N, Meyerson M, Lander ES, Neuberg D, Brown JR, Getz G, Wu CJ. Evolution and impact of subclonal mutations in chronic lymphocytic leukemia. Cell. Feb 2013, 14;152(4):714-26. doi: 10.1016/j.cell.2013.01.019.

25. Maekawa T, Fujii H, Horiike S, Okuda T, Yokota S, Ueda K, Urata Y Spontaneous remission of four months' duration in hypoplastic leukemia with tetraploid chromosome after blood transfusions and infection. Nippon Ketsueki Gakkai Zasshi 1989, 52:849-857

26. Miraki-Moud F, Anjos-Afonso F, Hodby KA, Griessinger E, Rosignoli G, Lillington D, Jia L, Davies JK, Cavenagh J, Smith M, et al. Acute myeloid leukemia does not deplete normal hematopoietic stem cells but induces cytopenias by impeding their differentiation. PNAS 2013, 110: 13576-81.

27. Antunez de Mayolo, J., Ahn, Y. S., Donald Temple, J. and Harrington, W. J. Spontaneous remission of acute leukemia after the termination of pregnancy. Cancer, 1989, 63:1621-1623.

28. Maywald, O., D. Buchheidt, J. Bergmann, C. Schoch, W.-D. Ludwig, A. Reiter, et al. Spontaneous remission in adult acute myeloid leukemia in association with systemic bacterial infection-case report and review of the literature. Ann. Hematol. 2004, 83:189-194.

29. Mitterbauer M, Fritzer-Szekeres M, Mitterbauer G, Simonitsch I, Knobl P, Rintelen C, Schwarzinger I, Haas OA, Silberbauer K, Frey K, Bibus B, Pabinger I, Radaszkiewicz T, Lechner K, Jaeger U Spontaneous remission of acute myeloid leukemia after infection and blood transfusion associated with hypergammaglobulinaemia. Ann Hematol 1996, 73:189-193

30. Musto P, D'Arena G, Melillo L, Cascavilla N, La Sala A, Ladogana S, Carotenuto M Spontaneous remission in acute myeloid leukaemia: a role for endogenous production of tumour necrosis factor and interleukin-2? Br J Haematol, 1994, 87:879880

31. Müller, C. I., M. Trepel, R. Kunzmann, A. Lais, R. Engelhardt, and M. Lübbert.. Hematologic and molecular spontaneous remission following sepsis in acute monoblastic leukemia with translocation $(9 ; 11)$ : a case report and review of the literature. Eur. J. Haematol. 2004, 73:62-66.

32. Claudia Müller-Schmah, Leticia Solari, Roland Weis, Dietmar Pfeifer, Carmen Scheibenbogen, Martin Trepel, Annette M. May, Rupert Engelhardt, Michael Lübbert, Immune response as a possible mechanism of long-lasting disease control in spontaneous remission of MLL/AF9-positive acute myeloid leukemia, Annals of Hematology, 2012, 91, 1, 27

33. Nakamura N, Mori M, Kimizima K Spontaneous complete remission in a 70 year-old man with acute myeloblastic leukemia with severe pneumonia. Rinsho Ketsueki 1989, 30:1835-1839

34. Nikolis J.S. Dynamics of Hierarchical Systems. An Evolutionary Approach. Spinger-Verlag Berlin Heidelberg, 1986.

35. Paul R, Remes K, Lakkala T, Pelliniemi TT Spontaneous remission in acute myeloid leukaemia. Br J Haematol 1994, $86: 210-212$

36. Claire Pluchart, Martine Munzer, Pierre Mauran, Michel Abély, Transient Remission of Childhood Acute Lymphoblastic and Myeloid Leukemia Without Any Cytostatic Treatment, Journal of Pediatric Hematology/Oncology, 2015, 37, 1, 68

37. Pui $\mathrm{C}-\mathrm{H}$, and Campana D New definition of remission in childhood acute lymphoblastic leukemia. Leukemia 2000, Volume 14, Number 5, 783-785

38. Armin Rashidi, Stephen I. Fisher, Spontaneous remission of acute myeloid leukemia, Leukemia \& Lymphoma, 2015, 56, 6, 1727

39. Sabaawy HE Genetic Heterogeneity and Clonal Evolution of Tumor Cells and their Impact on Precision Cancer Medicine. J Leuk, 2013, 1:4. http://dx.doi.org/10.4172/2329-6917.1000124

40. Sheinerman E.R. Invitation to Dynamical Systems. Dover Publications. 2012. 
bioRxiv preprint doi: https://doi org/10.1101/034132; this version posted January 1, 2017. The copyright holder for this preprint (which was not certified by peer review) is the author/funder, who has granted bioRxiv a license to display the preprint in perpetuity. It is made available under aCC-BY-NC-ND 4.0 International license.

41. Shlush LI, Zandi S, Itzkovitz S, Schuh AC. Aging, clonal hematopoiesis and preleukemia: not just bad luck? Int J Hematol. 2015 Oct 6.

42. Stiehl T, Baran N, Ho AD, Marciniak-Czochra A. Clonal selection and therapy resistance in acute leukemias: Mathematical modelling explains different proliferation patterns at diagnosis and relapse. 2014, http://arxiv.org/abs/1309.4246V2

43. Sutton LA, Rosenquist R. Clonal evolution in chronic lymphocytic leukemia: impact of subclonality on disease progression. Expert Rev Hematol. 2015 Feb;8(1):71-8. doi: 10.1586/17474086.2015.972930. Epub 2014 Oct 27.

44. Takahashi M, Koike T, Aizawa Y, Kashimura M, Hayatsu K, Nagai K, Abe A, Urushiyama M, Yagisawa K Complete remission in three patients with acute myeloblastic leukemia by administration of G-CSF without antileukemic agents. Am J Hematol, 1997, 56:42-44

45. Tzankov A, Ludescher C, Duba HC, Steinlechner M, Knapp R, Schmid T, Grunewald K, Gastl G, Stauder R. Spontaneous remission in a secondary acute myelogenous leukaemia following invasive pulmonary aspergillosis. Ann Hematol, 2001, $80: 423-425$

46. Vogelstein B, Papadopoulos N, Velculescu VE, Zhou S, Diaz LA Jr, Kinzler KW. Cancer genome landscapes. Science 2013. Mar 29;339(6127):1546-58. doi: 10.1126/science.1235122.

47. Wintrobe's Clinical Hematology by John P. Greer, Daniel A. Arber, George M. Rodgers. Wolters Kluwer / Lippincott Williams [et] Wilkins, 2014

48. Zhang J, Niu C, Ye L, Huang H, He X, Tong WG, Ross J, Haug J, Johnson T, Feng JQ, et al. Identification of the haematopoietic stem cell niche and control of the niche size. Nature 2003, 425: 836-41. 
Structural diagram of major ideas in the article.

Main idea

Entropy flow within normal hematopoiesis in leukemia

Mathematical model
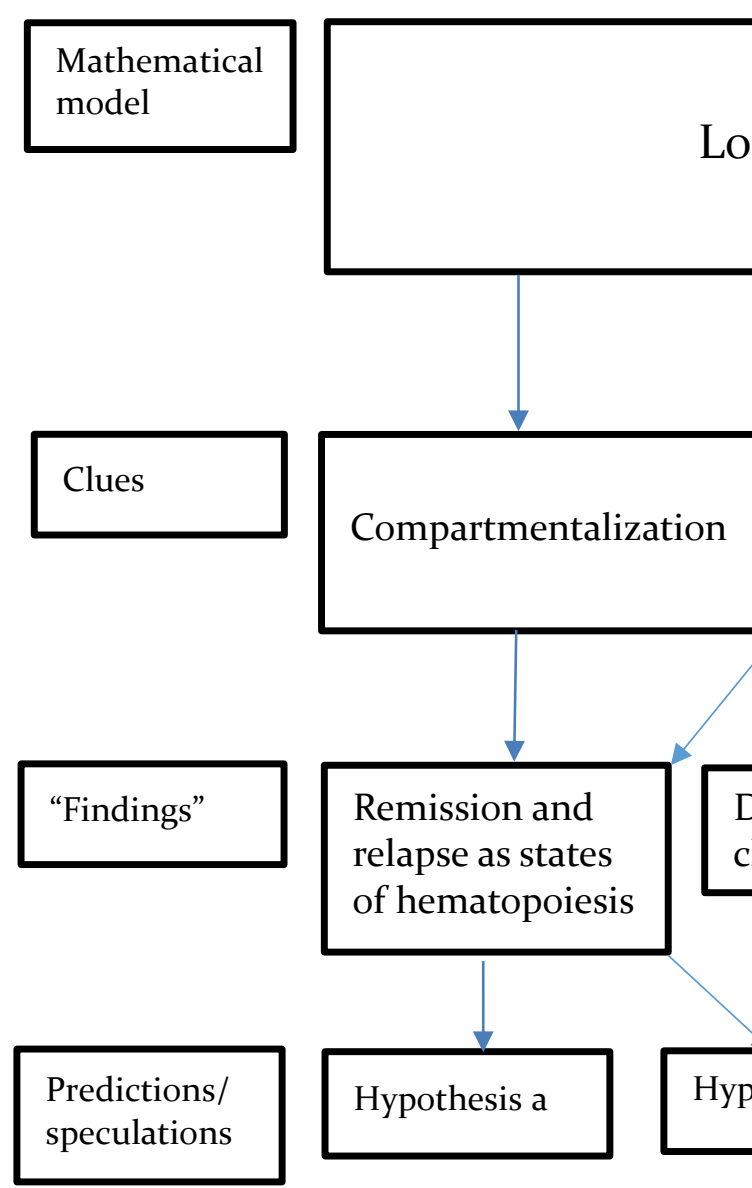

\section{Lorenz system}
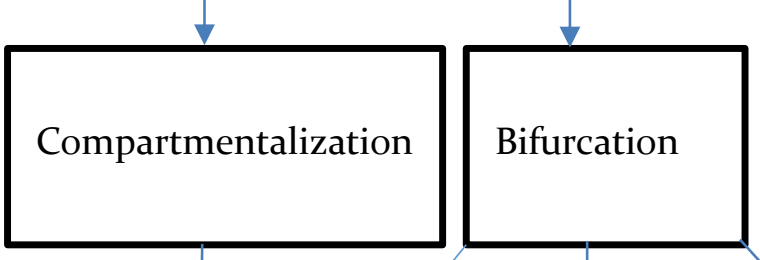

Spontaneous

states swap

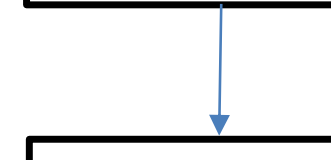

Remission and

relapse as states

of hematopoiesis
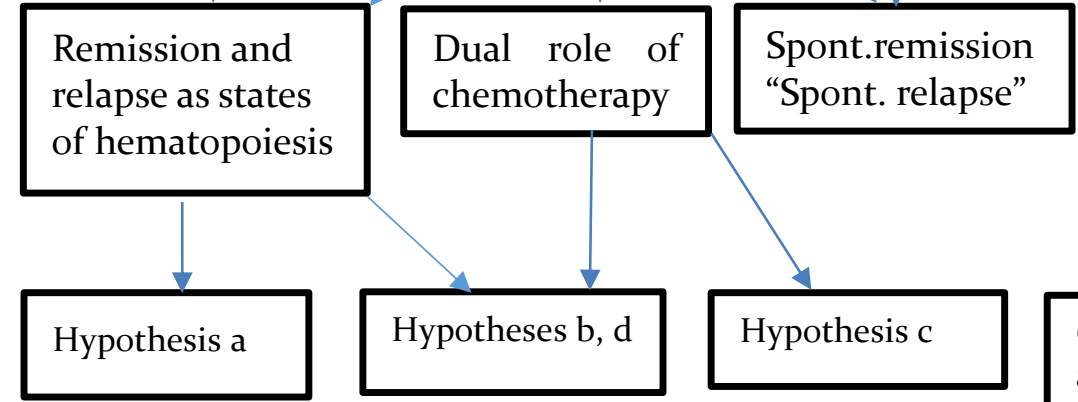

Cytopenia as an adaptation

Not all connections are shown.

The article in one sentence:

"Remission and relapse are states of normal hematopoiesis but not percentage of blasts". 
MATLAB simulation scirpt for the Lorenz System equations in the time interval $[0,100]$ with initial conditions $[1,1,1]$ and $r=1 / 2$.

clc

$\mathrm{p}=10$;

$\mathrm{b}=8 / 3$;

$\mathrm{r}=1 / 2$;

$f=@(t, a)\left[-p^{*} a(1)+p^{*} a(2) ; r^{*} a(1)-a(2)-a(1)^{* a} a(3) ;-b * a(3)+a(1)^{* a} a(2)\right] ;$

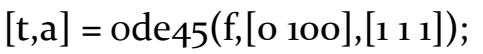

$\operatorname{plot}_{3}(\mathrm{a}(:, 1), \mathrm{a}(:, 2), \mathrm{a}(:, 3))$

\section{AUTHOR INFORMATION}

\section{Present Address}

Igor Alexeev. Välitalontie 83 C, Helsinki, oo66o, Finland 